\title{
ARTAUD LE MOMA, DE JACQUES DERRIDA
}

André Silveira Lage

Pós-Doutorando Pós-Lit/UFMG - Bolsista Fapemig

\begin{abstract}
RESUMO
A partir da conferência de Jacques Derrida, intitulada Artaud le Moma (1996), este texto pretende abordar a relação entre o tema do nome, do apelido de Artaud (“Artaud le Mômo” e suas diversas significações) e a temática do museu, da exposição das obras de Antonin Artaud no Museum of Modern Art de New York.
\end{abstract}

\section{PALAVRAS-CHAVE}

Assinatura, museu, Antonin Artaud, Jacques Derrida

Artaud le Moma é o título de uma conferência proferida por Jacques Derrida, em 1996, no Museum of Modern Art de New York, na ocasião da abertura da primeira grande exposição mundial das pinturas e dos desenhos de Artaud: Antonin Artaud: works on paper. Esse título, Artaud le Moma, não foi julgado apresentável ou decente pelo MoMa. A conferência, a única programada pelo museu, não divulgou o título dado por Derrida, mas apenas a indicação seguinte: “Jacques Derrida... will present a lecture about Artaud's drawings”.

Neste texto, privilegiarei como foco de estudo a relação entre o tema do nome, do apelido ("Artaud le Mômo” e suas diversas significações) e a temática do museu, da exposição das obras de Artaud, problematizada por Derrida da seguinte maneira:

Esta conferência tenta se aproximar daquele que se apelidara Artaud le Mômo. Seu título, Artaud le Moma fazia desde já alusão, certo, à temática do museu que se encontra de fato no cerne do meu propósito. (Moma, coisa bem conhecida, é o apelido familiar que damos, no mundo inteiro e por abreviação, ao Museum of Modern Art. Mas Artaud le Moma interroga também o estranho acontecimento que representa, em 1996, a exposição das obras de Artaud numa das mais 
consagradas instituições museográficas da metrópole nova-iorquina e do mundo. ${ }^{1}$

Jacques Derrida circunscreve assim o contexto e a direção de sua reflexão. O que ele anuncia aqui é uma cena de leitura: sua fala intervém como uma leitura do contexto, do lugar, da situação na qual ela se inscreve, o museu. Ela condensa o seu propósito, introduzindo-nos a problemática que será tratada ao longo de sua conferência, a saber, esse "estranho acontecimento que representa" expor as obras de Artaud no MoMa. Todo o trabalho de Derrida vai consistir em interrogar de maneira crítica essa relação entre a questão do museu e as obras de Artaud a partir da seguinte questão: “Quem faz o que?” Isto é: o que o museu faz à obra de Artaud e, reciprocamente, o que a obra de Artaud faz ao um museu? É este duplo movimento de um faire [fazer], de uma facture [feitura], ${ }^{2}$ que ele chama um “coup” [golpe, pancada], o acontecimento de um golpe, o modo de um pancada.

Em outras palavras: o que significa expor Artaud numa “instituição” contra a qual ele certamente se insurgiria? O que essa "instituição” faz a Artaud quando ela o celebra, o canoniza, o legitima? “O que significa museu de arte moderna? Um Museum Of Modern Art?”, questiona Derrida. O que se torna a questão do museu, quando esta é atravessada, incendiada pelo pensamento de Artaud? Ou ainda: “O que acontece num museu, num museu de Arte moderna, quando substituímos uma vogal por outra? Quando o $O$ se revocaliza em $A$, quando Momo torna-se Moma?”3

A desconstrução permite àquele que a pratica brincar com as palavras. E é exatamente o que faz Derrida quando ele brinca com essa semelhança fônica já no título censurado de sua conferência. Explorando a ressonância entre o apelido de Artaud (Artaud le Mômo) e o apelido do Museum of Modern Art (MoMa), ele marca o quiasma do A e do O (OA / AO MOMA ARTAUD), mostrando-nos pelo viés de tais operações que o "comentário" pode ser um eco do texto comentado, e que o texto comentado é ele mesmo um eco infinito, a modulação contínua de um léxico, de um nome ou de uma

\footnotetext{
${ }^{1}$ DERRIDA. Artaud le Moma: interjections d'appel, p. 11. Os trechos aqui traduzidos tentam "se aproximar" do original em francês, o tanto quanto possível. Traduzi-los foi um grande desafio não desprovido de impasses, dificuldades, hesitações e indecisões, próprias à experiência ou à travessia da tradução.

2 Facture é um empréstimo do latin clássico factura "fabricação", mas o campo semântico desse vocábulo é extremamente amplo. Em latim medieval, facture significa "criatura” e também "magia". Factura, derivado de facere "faire", culminou no antigo francês faiture "traço, rosto”. Uma facture é também uma conta para se pagar.

${ }^{3}$ DERRIDA. Artaud le Moma: interjections d'appel, p. 98.
} 
assinatura, como por exemplo, o nome de Antonin Artaud, que o próprio Artaud diz e escreve de diversas maneiras - ARTAUD, ARTO, ARTAU. Derrida ressalta ainda que se trata de um nome próprio cujas sílabas comportam a palavra arte e evocam a palavra martelo. O nome de Artaud traz a arte contra a qual ele sempre se insurgiu a golpes de martelo [ARTaud/mARTeau]. No entanto, Derrida assinala ainda um deslizamento importante:

Pois a partir do momento que o vocábulo Arte retoma o seu sentido comum, a partir do momento que esse vocábulo é atravessado por um conceito acreditado, a arte, a arte das belas-artes, a arte das Igrejas e dos Museus e dos Mercados, então o portador do nome, Artaud, não se contenta de denunciá-la, de invectivá-la, ele entende fazer obra contra ela, ele a espanca a golpes de martelo. Ele a espanca até a morte. $^{4}$

Artaud, le moma pode ser compreendido nesse sentido como um gesto de protesto radical contra a máquina na qual um museu se inscreve: o Estado, o Capital. Derrida reafirma a força da obra de Artaud, a partir de uma reflexão sobre o museu como lugar de conservação, de arquivamento, de mumificação, de santificação, de canonização. Essa é uma das questões que o interessa ao longo de sua conferência. E é o que Derrida parece sublinhar nessa passagem que, não por acaso, nos traz uma das definições de MoMa:

Aqui, esta instituição canonizante, este lugar de legitimação sacralizante dos tempos modernos, esta pirâmide de commémomarchémomification $^{5}$ pai-maternal e especulativa, nós o chamamos então MOMA, M-O-M-A.

Derrida agradece a chance dada por um museu, a chance de uma hospitalidade, pois um museu expõe obras originais e bane em princípio a reprodução. No entanto, a gratidão pelo MoMa não o impede de colocar a "séria e inesgotável questão do Museu". ${ }^{6}$ E ele a coloca a partir de Artaud, isto é, a partir de uma obra que, do início ao fim, nunca cessou de lançar golpes e pancadas contra a arte, o mundo da arte e a história da arte.

\footnotetext{
${ }^{4}$ DERRIDA. Artaud le Moma: interjections d'appel, p. 84.

5 “Commémomarchémomification” é uma palavra construída a partir da aglutinação de commémorer [comemorar], "moma”, [o apelido do museu], marché [mercado] e mumification [mumificação]. DERRIDA. Artaud le Moma: interjections d’appel, p. 83.

${ }^{6}$ DERRIDA. Artaud le Moma: interjections d'appel, p. 18.
} 
A questão do Museu será “sempre foudroyé por Antonin Artaud”, escreve Derrida. “Sempre Foudroyé por Antonin Artaud” indica o tema do raio [la foudre], do homem-trovão [l'homme-foudre], que será explorado em diversas passagens de sua conferência. Derrida diz “foudroyé” para explicitar primeiramente, como ele mesmo o indica,

a figura de uma aparição fenomenal, o acontecimento nomeado Antonin Artaud, sua existência meteórica, sua passagem dilacerante na literatura, na poesia, no teatro, nas artes visuais, sua aparição de raio luminoso, perigoso, mortal, excepcional, sua explosão de trovão também no céu de nossa história, de uma história da arte que ele teria querido atacar e virtualmente destruir o conceito. ${ }^{7}$

Mas não se trata de destruir somente o conceito de arte ou de história da arte. A destruição que reivindica Artaud não concerne somente o espaço por excelência da representação, que seja ele visto sob o prisma conceitual ou histórico. Essa destruição é muito mais ampla, muito mais fulminante. Trata-se, completa Derrida, de uma insurreição

contra uma maquinação, a máquina social, médica, psiquiátrica, jurídica, policial, ideológica, ou seja, um rede filosófico-política que se aliou à forças obscuras para reduzir este raio vivo a um corpo assassinado, torturado, estilhaçado, drogado, eletrocutado, sobretudo por um sofrimento sem nome, uma paixão inominável, a qual não lhe restava senão o recurso de re-nomear e de reinventar a linguagem. ${ }^{8}$

Foudroyer: fulminar, arruinar, abater, destruir. Derrida utiliza ainda a palavra foudroyé para descrever os traços de uma passagem, o tempo, o ritmo das obras ali reunidas. Lembra-nos que la foudre [o raio, o trovão] é uma palavra empregada por Artaud, de maneira recorrente, para falar justamente da experiência do desenho e, em particular deste desenho que, a partir de 1939, ele não soube mais dissociar da escritura. Quando Derrida retoma um léxico próprio a Artaud, ele consegue trabalhar os ecos deste léxico, suas ressonâncias. Trata-se aí de uma operação de leitura que brinca com as letras, que identifica vizinhanças sonoras, que trabalha a língua no próprio decorrer da análise. Como exemplo, citemos esta passagem a propósito das ressonâncias que cria Derrida entre a palavra foudre [o raio, o trovão] e as palavras, le foutre [a copulação e o esperma], la poudre [a pólvora do canhão], le fou [o louco]:

\footnotetext{
${ }^{7}$ DERRIDA. Artaud le Moma: interjections d'appel, p. 18-19.

${ }^{8}$ DERRIDA. Artaud le Moma: interjections d'appel, p. 20.
} 
Artaud nomeia duas vezes la foudre. Na palavra foudre, escutamos a explosão de um míssil, a deflagração do sopro ou a conflagração de uma bomba incendiária. Mas escutamos também, de longe ou de perto, outras palavras, que Artaud associa regularmente: perto de foudre, le foutre (a copulação e o esperma), que multiplica as afinidades com o vocábulo poudre (uma das palavras que aprecia Artaud para designar tanto a pólvora do canhão, a poeira seminal, a tinta, o pigmento pictural da cor - ou o que a destruição pelo fogo reduz às cinzas) e sobretudo com o monossílabo fou e então com a palavra mômo, que significa, entre outros coisas, le cinglé [o doido]. ${ }^{9}$

Artaud le mômo - lembremos - é o título de um livro de poemas escrito por Artaud em 1946. Trata-se de um livro que marca definitivamente o retorno de Artaud à poesia. Um dos poemas desse livro se intitula “Le retour d’Artaud, le Mômo” [O retorno de Artaud, o momo]. Retomando a leitura que Paule Thévenin fez deste título no seu artigo "Escutar/ver/ler", ${ }^{10}$ Derrida nos reconduz em direção à Marselha, onde nasceu Artaud e onde a palavra "Mômo" adquire uma infinidade de significações. Derrida ressalta primeiramente aquelas que giram em torno da infância, da ingenuidade, da inocência: "Mômo” é o môme [a criança]. "Mômo” refere-se também tanto à dupla mãe-criança (mam, mama, mum, môme, mômo) quanto à figura do mômo, do louco como o idiota da cidade, o inocente, o doido. Derrida observa ainda que momo deriva do catalão moma, que tem o sentido de monnaie [dinheiro ou de moeda], não muito longe de la momo, a mercadoria como gulodice, o bombom. O moma é assim a moeda, o dinheiro, como la momo seria a gulodice das crianças para comprar e para consumir. Referindo-se ainda à Marselha (que foi uma cidade grega), lembra-nos do poliglotismo neo-grego de Artaud, bem como da presença do grego na sua língua, na sua glossopoiése, e nos seus desenhos (por exemplo, ana, no alto à esquerda do desenho $A$ execração do Pai-Mãe - abril, 1946). Recorre ainda ao significado da palavra Mômo em Grego: “em Grego Mômo é o deus da zombaria, ele ilustra o terrível sarcasmo de uma careta que encontramos também no bobo, no bufão mômo”. ${ }^{11}$ Após a exploração das diversas significações dessa palavra que traz a marca de um nome, de uma assinatura, com todos os ecos e ressonâncias semânticas que ela supõe, Derrida propõe relacionar o que ele chama "estas duas genealogias familiar e semânticas, estas duas geografias do lugar, do corpo de Artaud”:

\footnotetext{
${ }^{9}$ DERRIDA. Artaud le Moma: interjections d'appel, p. 34.

${ }^{10}$ Ver THÉVENIN. Antonin Artaud: ce désespéré qui vous parle.

${ }^{11}$ DERRIDA. Artaud le Moma: interjections d'appel, p. 46.
} 
Por um lado, o retorno do Mômo, a criança, o inocente, o louco desarmado que retorna para processar a máquina que o detém e o destrói, corpo e alma; e esta máquina institucional é uma cultura ao mesmo tempo social, médica, psiquiátrica, policial, religiosa, política, estatal, metafísica - artística também (o museu é um desses poderes de fundação, de conservação, de legitimação, de canonização, de acumulação, um poder ao mesmo tempo público e privado (...); mas ao mesmo tempo, por outro lado, indissociavelmente, o requisitório desta criança inocente que traz as marcas do Mômo assassinado, mortificado, mumificado, ele dá também seus golpes, suas pancadas: é o enfurecer-se de uma zombaria satânica, a do deus Mômos, de suas blasfêmias, insultos, ataques, acusações e sarcasmos, de suas incriminações e recriminações. ${ }^{12}$

Artaud, le mômo, esse nome, essa assinatura, é o cúmplice de um deus da ironia que ri na sua cara e desafia todas as instituições culturais, "e a história da arte, e a disciplina do desenho, e o os critérios de avaliação bem feitos, as boas maneiras e o mercado da crítica de arte, de seus salões, de suas galerias, de suas fundações e de seus museus". ${ }^{13}$ Seus desenhos e retratos são um grito de protesto contra o "princípio do desenho”. Ele mesmo afirma a propósito de seus desenhos: "Rompi definitivamente com a arte, o estilo ou o talento em todos os desenhos que veremos aqui.” Proposição que, segundo Derrida, não é uma simples declaração teórica ou autobiográfica, mas um grito de ruptura com a arte das belas artes, com a preocupação da bela forma, do estilo, do arranjo, da estética ligada ao saber-fazer, à habilidade, à disciplina de escola, à experiência ou à experimentação técnica de um talento. $\mathrm{O}$ nome, a assinatura Artaud le Mômo, anuncia a própria destruição da arte e da história da arte.

Em 2002, essa conferência foi publicada pelas edições Galilée, com o título Artaud le Moma Interjections d'appel - subtítulo sobre o qual se estende longamente Derrida e que indica, evidentemente, um dos sentidos de sua intervenção: pedir a revisão de um processo. “Interjecter l’appel” é uma expressão que ele utiliza no sentido da linguagem do direito. Como nos mostra o filósofo, "Interjecter l’appel”

designa, no decorrer de uma ação, o procedimento de revisão do processo, lá onde o engano e a injustiça, riscam de ter sido autorizados, em seguida estabilizados, enfim legitimados por um julgamento anterior. Então pede-se a revisão de um processo para dar um fim à coisa mal julgada, em vista de se insurgir contra o julgamento de todos os juízes, os da Magistratura, das Igrejas, do Estado, da Família ou da Sociedade, contra o critério de todos aqueles que juram e julgam, todos os conjurados que criticam, avaliam,

\footnotetext{
${ }^{12}$ DERRIDA Artaud le Moma: interjections d'appel, p. 46.

${ }^{13}$ DERRIDA Artaud le Moma: interjections d'appel, p. 47.
} 
diagnosticam : os médicos, sobretudo o psiquiatra, os críticos de arte, os críticos literários, os moralistas e os padres, os professores, todos secretamente caucionados por algum julgamento de deus com o qual uma interjeição queria acabar. ${ }^{14}$

Artaud, aos olhos de Derrida, teria feito de tudo para proibir esta manifestação, esta exposição, esta exibição, esta cadaverização. Derrida diz ouvir Artaud “invectivar, amaldiçoar, zombar ou denunciar, interjeitar, blasfemar, jurar - conjurar. Fulminar, explodir. Contra tudo: A América, os Estados Unidos da América, a Arte, o Museu, a Modernidade, o Moma. Sobretudo o Moma, o qual Artaud teria rapidamente identificado com a figura do grande expropriador”, ${ }^{15}$ com a encarnação de um mal, com aquele que rouba o corpo de Artaud, barrando toda possibilidade de vida e transformando-o em cadáver. O Museu é lugar de coisa morta. O museu como hospital e a obra de arte como cadáver, tal seria a lição de Derrida?

\begin{abstract}
Jacques Derrida's conference titled Artaud le Moma (1996) will inform the present article by the way it will approach the name, Artaud's nick-name ("Artaud le Mômo" and its various significations), and the museum, specifically the exposition of the works of Antonin Artaud in the Museum of Modern Art in New York.
\end{abstract}

\title{
KEYWORDS
}

Signature, Museum, Antonin Artaud, Jacques Derrida

\section{REFERÊNCIAS}

DERRIDA, Jacques. Artaud le Moma: interjections d'appel. Paris: Galilée, 2002.

THÉVENIN, Paule. Antonin Artaud: ce désespéré qui vous parle. Paris: Seuil, 1993.

\footnotetext{
${ }^{14}$ DERRIDA Artaud le Moma: interjections d'appel, p. 102.

${ }^{15}$ DERRIDA Artaud le Moma: interjections d'appel, p. 101.
} 